\title{
Aspects of Textual Cohesion in Selected Poems of J.P. Clark-Bekederemo
}

\author{
Ebi Yeibo \\ Department of English \& Literary Studies, Faculty of Arts, Niger Delta University, Wilberforce Island, Bayelsa State, \\ Nigeria \\ Email: eyeibo@gmail.com
}

\begin{abstract}
Previous studies on J.P. Clark-Bekederemo's poetry have concentrated on literary and some linguistic features, highlighting the relation of theme and figuration in the works. However, such studies have not paid attention to the discourse and pragmatic aspects of the texts, which are crucial for a thorough description and interpretation of the writer's idiolect. This study, therefore, examines aspects of textual cohesion in the poems, using the methods and insights of discourse analysis. With Halliday and Hasan's (1976) cohesive devices viz: ellipsis, references, and conjunction, as the analytical platform, the study shows some linguistic strategies used by the poet to achieve inter-sentence connection in the poetry. It also shows the network of interdependencies among linguistic and non-linguistic features, which give the poetry a thoroughly cohesive structure. The aim is to demonstrate that cohesive ties have the potentials to combine with other elements of language to unify different parts of a text. The study enriches our perspectives not only on the language of J. P. Clark-Bekederemo's poetry, but also on the language of poetic discourse in general.
\end{abstract}

Index Terms - textual cohesion, J.P Clark-Bekederemo, poetry, discourse analysis

\section{INTRODUCTION}

As one of the leading lights of Nigeria's first generation of modern literary scribblers, J. P. Clark-Bekederemo's works have attracted prodigious acclaim and critical attention. However, from the corpus of available literature, it is obvious that there is an acute dearth of critical works on the language of the poet by language scholars. The inference of this thesis is that most of the critical investigations of the poet's oeuvre are literary and thematic in focus (see Eyoh, 1997). This is a sharp contrast to the considerable volume of linguistic studies that the works of such poets as Soyinka and Osundare have evoked. In fact, Eyoh's (1997) J.P Clark's Poetry: A Study in Stylistic Criticism, which examines and characterizes the writer's poetic idiolect from phono-stylistic, lexical and paralinguistic affective levels, remains the only full-scale linguistic exploration of the writer's poetry. Significantly, the scholar himself acknowledges the inherent limitation of this work and suggests that it has opened up new vistas for research on the poet, particularly from the perspectives of syntax, tenor of discourse and graphology.

The present study seeks to fill the gap left by Eyoh's work, in the area of Discourse Analysis, by focusing on aspects of textual cohesion in the writer's poetry. Discourse itself is concerned with "... how different parts of the text are interwoven to achieve desired results" (Alo, 1998, p.131). In Crystal's (1987) view, it implies how sentences work in sequence to produce coherent stretches of language. Hornby (2000) sees the concept as

The use of language in speech and writing in order to produce meaning. Language that is studied, usually in order to see how the different parts of a text are connected. (p.331).

The cardinal point is that poetry texts are verbal constructs which can be classified as discourse, in the sense that they contain all the "properties" of discourse viz: structure, meaning, action (see Schiffrin, 1987). Although Widdowson (1984) avers that, "it is common to find instances of language use (in poetry) which cannot be accounted for by grammatical rules" (p.162), they are sequences of sentences, sequences which are not random but well-formed by virtue of what Halliday and Hasan (1976) call "cohesive" relationships tying one sentence to another. In fact, poetry is a social discourse, like other genres of literature (i.e. drama, prose) because we can relate the formal linguistic patterning in the poetry text to the given communicative context.

\section{THEORETICAL FOUNDATION}

According to Schiffrin (1994), discourse is often discussed along formalist and functionalist paradigms (p. 20). In formalist paradigm, also known as structuralist, discourse is described as a particular unit of language above the sentence. In functionalist, also known as emergent or interactive paradigm (May et al, 1992), it is described as a discipline which focuses on language use. These definitions essentially underpin the difference between formalist and functionalist approaches to discourse analysis. As summarized by Leech (1983), formalists tend to regard language primarily as a mental phenomenon, while functionalists regard it primarily as a social phenomenon (p.46).

The structuralist approach is particularly favoured by Harris (1952), the first scholar to refer to discourse analysis who, among other things, was of the opinion that discourse analysis should take into account other data e.g. the 
morpheme, clause, sentence, the proposition, turns, speech actions and speech events, etc, believing that the sentence is the level (unit) of which discourse is composed. One strong criticism against this reliance on definitions and analysis of the smaller unit of "sentence" is that the units in which people speak do not always seem like sentences. This implies that, the structuralist or formalist approach to discourse analysis might not be sufficient for the analysis of spoken discourse which, in the words of Chafe $(1980,1987,1992)$, is often produced in units with "intonational and semantic closure not necessarily syntactic closure", and other discourses in which information is not organized in underlying grammatical structure. In other words, formalist discourse analysts work with what Lyons (1977) describes as "system sentences" - those that satisfy the requirement of well-formedness (p. 385, 387). But since texts (i.e. literary) are not always composed of "system sentences" but also "text sentences" whose interpretations are context-dependent, it can be said that linguistic formalism is of limited significance in literary studies. This means that the approach has limited application to literary texts since it applies more to the analysis of dramatic discourse, which is closer to the spoken text than other genres of literature. This is because texts of all kinds have internal dependencies such that they don't need to be well formed to be acceptable. Halliday argues that language is a social semiotic and as such, needs to be studied in terms of the lived experience of its users rather than an abstract system of logically consistent rules.

In functionalist paradigm, on the other hand, the analysis of discourse is the study of any aspect of language use (Fasold, 1990, p.65). This analysis is not restricted to the description of functions which these forms are designed to serve in human affairs (see Brown and Yule, 1983, p.1). Discourse is assumed to be interdependent with social life, such that its analysis necessarily intersects with meanings, activities, and systems outside of itself. Analysts who adopt the functionalist view of discourse rely upon the strictly grammatical characteristics of utterances as sentences, than upon the way utterances are situated in contexts. The incontrovertible reality is that language and society functionally depend on each other.

The systemic functional grammar that provides the theoretical framework for the present study, is subsumed within functional linguistics. The interest of this grammar is not only in describing the structure of language, but also in explaining the properties of discourse and its functions. It revolves around the work of J.R. Firth in general and M.A.K. Halliday in particular. In Hallidayan (1970) perception, a formal feature is stylistic if it has a particular meaning, effect or value. This notion emphasizes how language functions in texts and the nexus between language and what it is used for, or to achieve. The critical point here is that, whatever linguistic resource that is worth describing must be put to use, in the sense that the description and interpretation are necessarily based on the situational variables that prompted its use. Hence Oha (1994) posits that the approach recognizes the interdependency of style, meaning and context of situation and that the latter should not be subjected to second fiddle position, or ignored, in the analysis of style (p.730).

In Systemic Functional Grammar, language structure is analyzed along semantic, phonological, lexical and grammatical lines. Language function, on the other hand, is examined from three angles viz: ideational, interpersonal and textual. These are referred to as the metafunctions of language. The ideational metafunction of language is synonymous with the field of discourse i.e. the subject matter or propositional content of the text and the context of language use i.e. is it a religious or socio-political subject? The interpersonal or interactional function, at another level, refers to the tenor of discourse i.e. the social relationship that exists among participants in a specific discourse situation, which can influence or shape language use. The textual aspect is particularly germane to the present study. It is concerned with the mode. Leech and Short (1985) see Halliday's textual functions of language as "...ways of using language to organize, understand and express information for effective communication" (p.209). The main point is that, the textual metafunction relates what is said in a text to ideas outside the discourse, as we shall demonstrate in the present study. It is concerned with the internal organization and communicative nature of a text. In this model, cohesion is examined both lexically and grammatically. The lexical aspect examines sense relations and lexical repetitions. The grammatical aspect on the other hand, examines repetition of meaning through reference, substitution and ellipsis, as we shall see in the present study.

Importantly, we can glean from the foregoing that the view of discourse analysis we apply in this study is that which employs the tools of grammarians to identify the roles of wordings in passages or texts, and employs the tools of social theorists to explain why they make the meanings they do. This is inevitable because an interpretation of a literary work as a piece of discourse, involves correlating the meaning of a linguistic item as an element in the language code with the meaning it takes on in the context in which it occurs.

\section{The CONCEPT OF TEXTUAL COHESION}

The concept or notion of cohesion simply refers to the relations or interdependence among linguistic elements in a text, for the ultimate realization of textual meaning. Osisanwo (2003) sees it as “... the linguistic means by which a text functions as a single unit" (p.31). According to Alo (1995), It is “... essential for showing relationships among different parts of an essay" (p.99). The aspect of meaning is very crucial in any organic relations of linguistic items for, the underlying function of such relations is to enhance the encoding and decoding process of meaning or textual message. Osisanwo (2003) explains that, "If the message is to be meaningful, the various parts or segments must be brought together to form a unified whole" (p.31). Halliday and Hasan (1976) corroborate this viewpoint inter alia:

The concept of cohesion is a semantic one; it refers to relations of meaning that exist within the text, and that define it as a text. Cohesion occurs where the interpretation of some element in the discourse is dependent on another. 
As we have indicated in the preceding section, textual cohesion is achieved through lexical and grammatical elements. This thesis explains Osisanwo's (2003) view that the concept “...accounts for how ...tests are held together lexically and grammatically" (p31). Grammatical devices of cohesion include: substitution, ellipsis and reference; while lexical cohesion is achieved through collocation and reiteration. Conjunction, which is used to achieve conjunctive relations in a text, is on the "borderline" between lexical and grammatical cohesion.

\section{BRIEF BIO-DATA OF THE POET}

Born December 6, 1933 in Kiagbodo in the Ijaw area of present-day Delta State of Nigeria, to Ijaw and Urhobo parents (His father was Ijaw and mother Urhobo), Johnson Pepper Clark-Bekederemo had his primary school at Okrika (1940-1948) and Jeremi (1948), before proceeding to Government College, Ughelli, for his secondary education (19481953). He attended the University of Ibadan between 1955 and 1960. At Ibadan, together with a handful of other writers, he played a prominent role in establishing Nigeria and the continent of Africa as one of the major centres of Literature in English in the twentieth century. Of his Ibadan years, Wren (1984) remarks that Clark-Bekederemo "showed the most precocious talent that West African literary history had yet seen." The poet has worked as an information officer, journalist, and University professor. Apart from his poetry, Clark-Bekederemo is also a frontline African dramatist and scholar. He has also written a novel (travelogue) America, their America (1964), which is an account of his sojourn in America as a Parvin fellow at Princeton University (1962-63)

\section{Contextual Issues in the Poetry}

That language and context are two inseparable phenomena is a fact that has been long standing and established (see Leech, 1983, p.13). Morley (1985) points out that, "context serves to itemize those aspects of the situation which have a bearing on the form used" (p.4). The critical point in that, context is an important aspect of language use. As we shall demonstrate in the analysis of the texts, the true meaning of a text can be thought of as a relationship between its linguistic elements and whatever contextual evidence is available for clarifying it. In J. P. Clark-Bekederemo's poetry, certain variables constitute the context of situation. These include: genre type, background experiences of the poet, socio-political realities, and subject-matter.

\section{TeXtual AnAlysis}

Following Halliday and Hasan's (1976) view that cohesion in texts is achieved through the following five lexical and grammatical devices viz: substitution, ellipsis, reference, conjunction and lexis, we shall examine cohesion in ClarkBekederemo's poetry with three of these devices as our guide (i.e. ellipsis, reference, conjunction). We believe that the three aspects selected for exploration, would bring out the significant cohesive designs and patterns in the poems under study. We also need to establish that it is impossible to examine all the poems of a writer like Clark-Bekederemo, whose literary career has spanned over fifty (50) years (i.e. 1958- date), in a study of this nature. We shall, therefore, focus on representative poems from the following collections; Poems (1962), Casualties (1970), State of the Union (1985), A Lot from Paradise (1999), Of Sleep And Old Age (2003), and Once Again a Child (2004). We believe that these poems would not only sufficiently exemplify the various cohesive devices, but would also help us to achieve a temporal balance between the writer's early and later poetry.

\section{A. Elliptical Operation}

Ellipsis refers to the omission of items in a sentence. The omitted item may have appeared before the omission or after it and may not be recoverable at all from the sentence. The first category of ellipsis can be referred to as cataphoric ellipsis while the second is anaphoric. The third category can be described as zero-ellipsis and can be referred to as exophoric ellipsis, for, the discourse analyst has to look beyond the sentence to recover the omitted item.

Asiyanbola (2005) identifies eight types of ellipsis that can occur in sentences: ellipsis of subject, ellipsis of subject and auxiliary, ellipsis of auxiliary only, ellipsis of predicate, ellipsis of the whole predication, ellipsis of subject and predicator and ellipsis of adverbials (p.174-175). Olaosun (2006), using the example of the design in commodity advertisement, points out that ellipsis serves the following purposes: to serve the grammatical purpose of indicating word omission and "as pragmatic indicator that there are more things to be written than are written" (p.78). He points out further that when the omitted item is not recoverable from the text, ellipsis serves to give a discourse or a text "some kind of interpretive elasticity". In what follows shortly, we shall consider elliptical practices in the poems under study.

This device is used in such poems as "A photograph in the Observer" (Casualties), "Cave Call" (A Decade of Tongues), etc. It is, however, more strategically used in "Benin Sacrifice" (Casualties), which we analyze here to exemplify the textual role/ function of the device.

In "Benin Sacrifice", the strategy is copiously employed. Two types are noticed: ellipsis signaled by the graphological mark (...) and those not marked at all. Ellipses that are marked are basically zero type as no basic sentence element is missing from the texts in which they occur. This device is used in connecting what is said with what is not verbalized, indicating that the two are equipollent and thereby impress on the readers the question what else needs be said that has not been said. Ellipsis is used in the last line of five of the six-stanza poem. This makes them stand out 
for interpretation. Unmarked ellipsis is noticed in the second and fourth stanzas of the poem reproduced and analyzed below:

Stanza 2: $\quad$ In the glare before dark

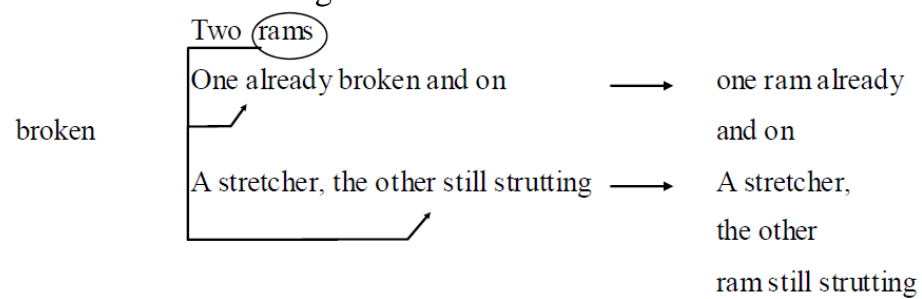

On his own steam...

ram still strutting

Stanza 4:

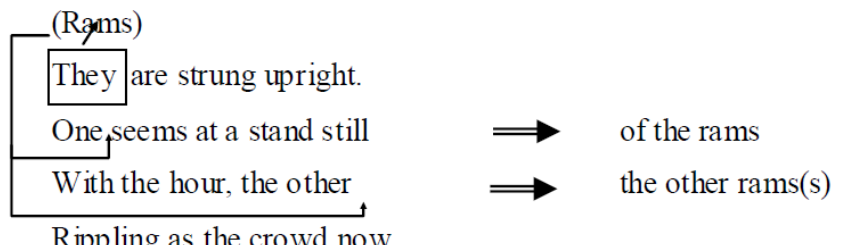

And many decades before...

In Once Again A Child, there is no instance of elliptical operation, especially the one indicated by elliptical dots. In Of Sleep and Old Age, there is only one instance found in "My Father's House". The whole poem is a one-sentence poem with no predicator. This type of ellipsis is known as verbal ellipsis or using the words of Asiyanbola (2005), ellipsis of predicator. There is also an instance of Zero ellipsis in the poem as in the expression "Now, not even an echo..." This expression, as could be noted, lacks both the subject and the predicator. This lack of essential elements relates to or amplifies the sense of loss and degeneration experienced by the household being described in the poem. It may be necessary to reveal the internal structure of this expression to show the points at which elements are omitted:

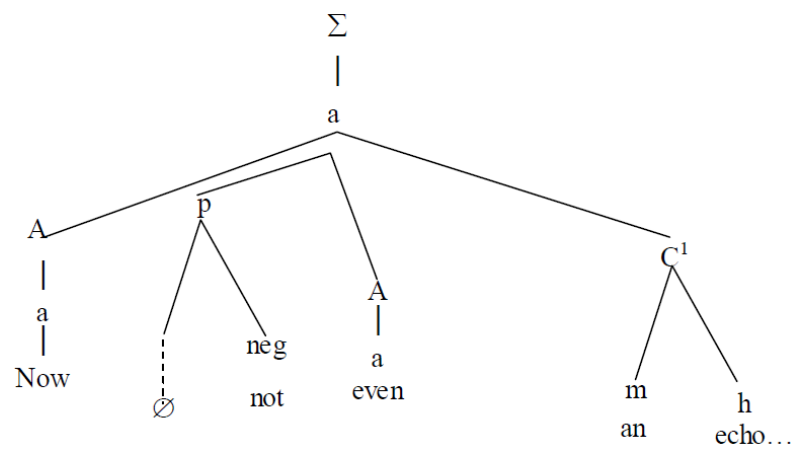

As indicated by the null symbol (o) in the tree diagram analysis above, the expression "there is" is lacking in the sentence. The zero ellipsis graphologically marked by the dots (...) is indicative of the mood of the poet (narrator). It is capable of producing several appeals in the poem. It can be indicative of the fact that the matter at stake is more than what words can express. It can also serve to express the disappointment felt by the narrator and infect readers with the seem emotion.

Also, in A Lot From Paradise, there is no instance of elliptical operation. We find it in seven poems in Poems (1962): "Ivbie or Oya (a song of wrong)", "His Excellency the Masquerader", "Boeing Crossing", "I Wake to the Touch", "Cave Call", "Benin Sacrifice" and "Easter 1976".

The rarity of ellipsis in all of these poems point to their unity. This unity also serves to reduce the heuristic tasks of readers. The point also relates to the simplicity and clarity of the poems. Based on these findings, it can be established here that the poems under study are characteristically simple and clear.

\section{B. Reference}

Inter-sentence connection or cohesion is also achieved in the poetry under study through reference. Generally, in texts of all kinds, inter-sentence connection through reference is expressed through pronouns (personal, interrogative, indefinite, etc), demonstratives, adverbs (locative and temporal). Pronoun is certainly the most basic of the English referential elements. It is the dominant feature of the poems under study. A few of the cases are presented and analyzed shortly. For clarity, the entire poems illustrating the feature are presented and the intra and inter-sentential linkages are shown by analytical string.

\section{Progress (State of the Union)}




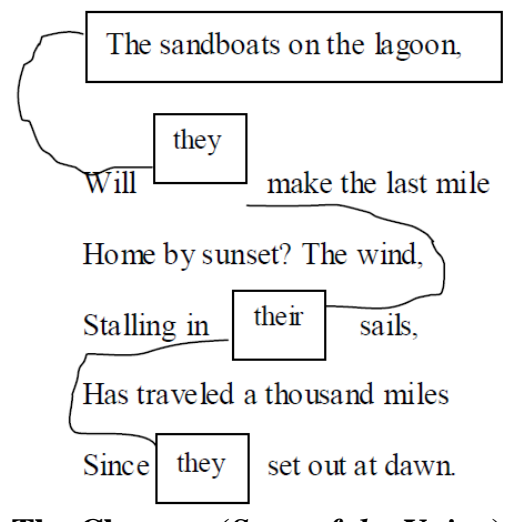

The Cleaners (State of the Union)

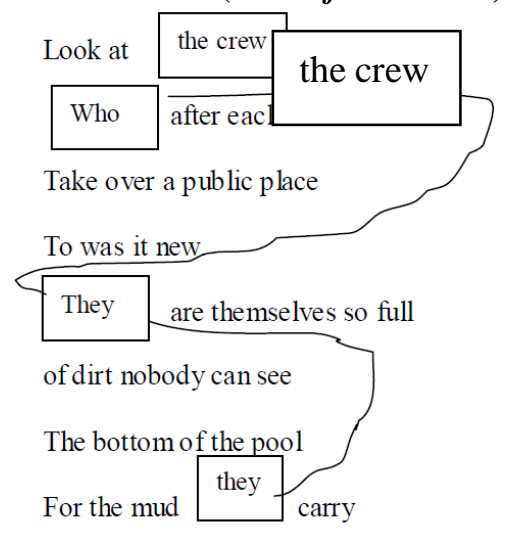

And cast so freely at a few.

The analysis above clearly shows that the poems are highly unified because they foster adequate reference. This is very typical of almost all the poems in the three volumes chosen for this study, as revealed further in the following analysis of another poem drawn from "Of Sleep and Old Age" (2003):

Niger Delta Burning

The once evergreen trees

Now standing sear in the swamps

Lift their arms to the skies

They are filled with gas clouds and flares

And all the flotsam oil in the rivers

Brings home on the banks is fresh blight...

Going by the analysis of the three poems above, particularly because of the ways the various parts are properly linked, J. P. Clark-Bekederemo's poetry can be said to be written in clear style. However, we have few cases of pronominal that do not foster adequate reference, particularly in "Victoria Island Revisited" (Poems) The poem is reproduced below:

They say the sea is raging at the Bar

Beach of Lagos, knocking at the doors

Of homes built by contract finance

On public land for a few to collect

Millions. How has it harbored

For so long this structure with a bottom

So patently false and rotten

It can not but founder one day?

Next they will be drawing upon

The public purse to salvage the bulk.

In the poem above, J. P. Clark-Bekederemo does not furnish readers with an antecedent referent to the pronoun "they". Since pronouns ought to presuppose the existence of their referent, the use of "they" in the poem can be said to provide a deviant example. The referent of this pronoun is not clearly discernible except readers do some semantic calculation. A close study of the poem indicates that the referent of the pronoun is the government (federal, state or local) or people in positions of authority in the country. The expression "drawing upon the public purse" points to the referents that are not explicitly mentioned. The expression suggests authority and power, to draw upon public funds, and it is only people in government that have such powers and authority. As used in this poem, the pronoun irregularity 
is a self-protectionist device, used by the poet in order not to incur the wrath of anybody in position of authority, for instance, considering the fact that the poem is an exposition of the negligence and deception of the Nigerian leaders.

Similarly in "An epidemic without a name" reproduced below, the pro-form "one" and pronoun "it" do not foster readers with adequate references":

Another one gone

It was never like this before

Not when there is no war

Or a dread disease widespread

What feast among the dead

Calls them home at such a run?

Fear beats the drum

Let them run who can

Fear beats the drum.

In the poem reproduced above, the following words are used in a way that is not in conformity with their convention of use: "one", "it", "this", "them", and "the drum". None of them has an antecedent or any referent. The poem is therefore structurally loose. However, the following words used in the poem provide clues to their referents: "war", "disease", "the dead", "call ... home". All of them connect logically with the title, "An Epidemic Without a Name". By grammatical calculation, the pro-form "one" in the first line of the poem can be said to refer to the rate at which the unnamed epidemic claims the lives of people. The idea of homecoming at a run describes that sort of killing or death characteristic of the spread of an epidemic in an area. The "drum", as used in the poem, is a drum beaten by death and thus the reason why people must run. The second to the last line of the poem illustrates what Halliday and Hasan (1976) describe as "substitution by zero" (p.145). The verbal element "run" which is ellipted in that line is replaced with nothing. However, by looking backward in the poem, the word is recoverable.

The dominant demonstrative used in the "The Casualties" (Casualties), for instance, is 'those'. It occurs six times in the poem. Its discourse function is to make reference to the casualties of the Nigerian civil war, which is the subject of this poem. This non-inclusive demonstrative, considered alone, can be said to serve in counting the poet out of the group of casualties of that war, but if considered in the context of "the casualties are not only", it points to the fact that there are other casualties. These other casualties are indicated by the personal pronoun "we", used in three places in the last part of the poem. The two combine in the poem to answer the question "who are the casualties?", which the title of the poem might impress on readers. They indicate that "we" and other people are the casualties of the Nigerian civil war. The poet defines clearly the other referents of the word "casualties" as the dead, wounded, prisoners, exiles, and those who lost persons and property. The vividness of the poem is further enhanced by the use of locative and temporal adverbs, which serve in relating the event in the poem to the past and present times. Generally, the basic function of the adverbial element is to make textual information specific and splendid. The locative adverbs "there" ( 1 st $s t a n z a)$ and "outside" ( $2^{\text {nd }}$ stanza), and temporal adverbs "by night" (stanza 2, line 1), "by installment" (stanza 1, line 4), serve this basic function in the poem.

Similarly, in "Party Song" (Casualties), the locative adverb "here" is repeated three times in the first stanza of the poem viz:

Here we mill drinking by midnight

Here we mill bobbling by fairylight

Here we mill glowing by dimlight

Other locative adverbs used in the poem are "away" in "A floor away" (line 1, stanza 2) and nominal adverbial i.e. "by night and day". All these contribute to specificity of information and narrative splendour in this poem.

\section{Conjunction}

Conjunctive elements also serve as elements of cohesion in the poetry under study. Functionally, conjunctive elements help to link clauses (i.e. both major and minor) in discourse. In J.P Clark-Bekederemo's poetry, the additive 'and', for instance, links harmonious natural order, while the contrastive 'but' brings together contradictory or negative phenomena i.e. conflict in human relations. For exemplification or illustration, the cases of this device found in "New Year" (A Decade of Tongues) and "The Reign of the Crocodile" (Casualties), for instance, are strategic.

In "New Year", Bekederemo uses the additive conjunct "and" in the third line of each of the first and second stanzas of the poem. This device is used in connecting the idea of the natural flow of time into time and in presenting a harmonious picture. In the third and last stanzas the adversative "but" is used to contrast the harmonious metaphors in the first and second stanzas. The harmonious natural order suggested by the imagery of the continuously flowing water is negated by "artificial" walls which men create amongst themselves (see "self-split selves" in the last line of the second stanza).

Similarly, in the "The Reign of the Crocodile", the additive conjunct is copiously used. Four occurrences of this cohesive device are noticed in the poem but only one of them actually connects related ideas. Their use negates the general notion that the additive conjunct "and" should be used in connecting items of equal status. In the context of this poem, the additive "and" is used to model the narrative formula in traditional folktales from which the subject of the poem is derived. The only "normal" additive conjunct in the poem is the tenth line of the first stanza: 
He punted upon his tail,

And like the whirlpool of Gangana,

Swallowed his own head

If the interrupting clause is removed or deleted from the excerpt above, the pattern we would have is:

He punted upon his tail

And swallowed his own head

If this pattern is compared with the ones in the second stanza of the poem, the two instances of the use of conjunct described above will become clear:

And so for six months a mighty river

Silted in the mouth

Lacking distributaries,

For six months field upon banks

Crackled to the sky,

Lacking distributaries

And in caves flooded by them

Tied feet and tongue at the pleasure of the leopard

And the loingatms peeled at palms.

\section{CONCLUSION}

In the foregoing discourse, we have shown that J. P. Clark-Bekederemo's poetry under study, reflects significant aspects of textual cohesion. We have shown how the poet links various words and linguistic patterns in his poems to achieve connectedness of meaning. Specifically, we have shown that linguistic devices such as ellipsis, reference, and conjunction, have text-binding value i.e. they can function as agents of cohesion in a text. This confirms our earlier position that poetry is discourse, in the sense that it shows "... how different parts of the text are interwoven to achieve desired results" (Alo, 1998, p.131).

\section{REFERENCES}

[1] Alo M.A. (1998). Style in Language and Communication. Port-Harcourt: Aeddy Link.

[2] Alo, M.A. (1995). Applied English Linguistics: An Introduction. Port-Harcourt: Aeddy Link.

[3] Aremo, B. (1997). Introduction to English Sentences. Vol. 2 Ibadan: Caltop Publishers.

[4] Brown, G. and Yule, G. (1983). Discourse Analysis. Cambridge: CUP.

[5] Clark-Bekederemo, J.P. (1962). Poems: Ibadan: Mbari.

[6] Clark-Bekederemo, J.P. (1970). Casualties. London: Longman.

[7] Clark-Bekederemo, J.P. (1985). State of the Union. London: Longman.

[8] Clark-Bekederemo, J.P. (1999). A Lot from Paradise. Lagos: Malthouse Press Ltd.

[9] Clark-Bekederemo, J.P. (2003). Of Sleep and Old Age. Lagos: Crucible Publishers Ltd.

[10] Clark-Bekederemo, J.P. (2004). Once Again a Child. Ibadan: Mosuro.

[11] Crystal, D. (1987). The Cambridge Encyclopedia of Language. Cambridge: CUP.

[12] Eyoh, L. (1997). J.P. Clark's Poetry. A Study in Stylistic Criticism. An Unpublished Ph.D Thesis, University of Port-Harcourt.

[13] Fairclough, N. (1989). Language and Power. London: Longman.

[14] Fairclough, N. (1992). "The Appropriacy of “Appropriateness". In Fairclough, N. (Ed.) Critical Language Awareness. London: Routledge.

[15] Fairclough, N. (2000). "Discourse, Social Theory, and Social Research: The Discourse of Welfare Reform." In Journal of Sociolinguistics. 4 (2), pp. 163-195.

[16] Halliday, M.A.K. (1970). "Language Structure and Language Function.” In Lyon, J. (ed) New Horizons in Linguistics. Harmondsworth: Penguin Books.

[17] Halliday, M.A.K. (1973). Explorations in the Functions of Language. London: Arnold.

[18] Halliday, M.A.K. and Hasan, R. (1976). Cohesion in English. London: Longman.

[19] Harris, Z. (1951). Hermes or a Philosophical Inquiry Concerning Language and Universal Grammar. Menston: Scholars Press.

[20] Harris, Z. (1952). “Discourse Analysis: A Sample Text.” In Language. Vol. 28, pp.1-30.

[21] Hornby, A.S. (2000). Oxford Advanced Learner's Dictionary. $2^{\text {nd }}$ ed. London: Routledge.

[22] Leech, G. (1983). Principles of Pragmatics. London: Longman.

[23] Lyons, J. (1977). Semantics. Vols 1 \& 2. Cambridge: CUP.

[24] Oha, O. (1994). Language in War Situation: A Stylistic Analysis of the War Speeches of Ojukwu and Gowon. An Unpublished Ph.D Thesis, University of Ibadan.

[25] Olaosun, I.E. (2006). Language and Visuality in Selected Commodity Advertisements in Some Nigerian Newspapers. An Unpublished Ph.D. Thesis, University of Ibadan.

[26] Olateju, M. (2004). Discourse Analysis: Analyzing Discourse in the ESL Classroom. Ile- Ife: OAU Press Ltd.

[27] Onadeko, T. (2000). "Discourse Analysis: The Fundamentals." In Babajide, A. (ed) Studies in English Language. Ibadan: Enicrownfit Publishers.

[28] Osisanwo, W. (2003). Introduction to Discourse Analysis and Pragmatics. Lagos: Femolus-Fetop Publishers.

[29] Schiffrin D. (1994). Approaches to Discourse. Cambridge: Blackwell. 
[30] Schiffrin, D. (1987). Discourse Markers. Cambridge: CUP.

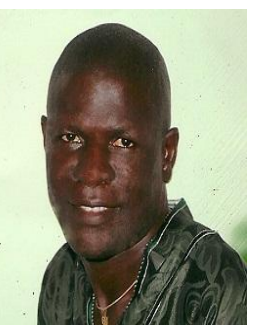

Ebi Yeibo was born in Bomadi, Delta State, Nigeria, on February 24, 1969. He obtained degrees in English from the Delta State University, Abraka (1996) and the University of Ibadan (2000), Nigeria, specializing in discourse analysis and stylistics.

He teaches stylistics, discourse analysis, applied linguistics, semantics and history of the English language at the Niger Delta University, Wilberforce Island, Bayelsa State, Nigeria, and has published scholarly papers on these areas in local and international journals. An award-winning poet, his published volumes of poetry include: Maiden Lines (Ibadan: Akol Press, 1997), A Song for Tomorrow (Ibadan: Kraftbooks Ltd, 2003), and The Forbidden Tongue (Ibadan: Kraftbooks Ltd, 2007).

Mr. Yeibo is a member of various professional and learned associations in Nigeria: Association of Nigerian Authors (ANA), Linguistic Association of Nigeria (LAN), and Nigerian Institute of Public Relations (NIPR). 